\title{
Discussion on the classroom teaching model of task-driven and education combined with research in Computer programming courses
}

\author{
Lanzhen Chen ${ }^{\mathrm{a}, \star}$, Rudan Lin, Xiaopeng Li \\ School of Information Engineering, Gannan Medical University, Ganzhou 341000, China \\ adanrou_2006@qq.com
}

Keywords: pharmaceutical industry; workflow; task-driven; computer programming.

\begin{abstract}
Computer programming courses is a compulsory course in many universities. Learning this course is helpful to cultivate students' ability of analytical thinking and dealing with issues, to promote the formation of logical thinking and rigorous scientific attitude, to promote the innovative development of other disciplines by effective use of information technology. But for a long time, computer programming courses is generally considered as the most difficult courses to understand and study. At present, some colleges and universities are exploring "task-driven method" in the teaching of computer science and application. As medical universities, if the task can be combined with mastery of teaching, learning and research of program design course, can greatly increase not only the students ' interest and professionalism, will also contribute to innovation of the course reforms. From this study courses in the program design of medical professional conduct industry research, the members of the research through the understanding of the industry process to think about computer programming ideas; to help students to use learning resources actively to carry out the study more effectively.
\end{abstract}

\section{Introduction}

Computer programming courses is a compulsory course in many medical colleges and universities. Learning this course is helpful to cultivate students' ability of analytical thinking and solve problems, thereby contributing to develop logical thinking and rigorous scientific style. It is effectively to promote innovation and development and to lay a good foundation for other disciplines by using information technology. But all along, it is considered by students is more difficult to master a course, the main reasons are follows:

(1)The boring content and rigorous grammar getting started is difficult.

(2)The quick rhythm, the limited time and the lack of interaction between teachers and students in multimedia classroom teaching cause the phenomenon of disgusted studying is widespread. Knowledge is not in time to digest, let alone learn proactively.

(3)There are difficult to cultivate students' interest because of the teaching task did not reflect the career-oriented, lack of School-Enterprise (Hospital) collaborative teaching arrangements and the project-driven were not closely linked with learn to work in the future.

(4)There is a great limitation in traditional education model which influences the teaching effects directly. The single model of assessment improves students' ability of test-taking, but detained the habit of independent thinking, analytical issues and innovative spirit.

\section{Research question and hypothesis}

The author is a university teacher of computer professional courses, has carried on the deep thinking to the present problems, if can put the industry task and program design combined with mastery of teaching, learning and research of program design course, can not only enhance the students ' learning interest and professional quality, but also to the innovation of curriculum reforms. Therefore, the members of author's research developed the teaching innovation of "task driven teaching method" on computer programming courses in Gannan University. The research group is mainly to solve the following problems:

(1)How to reflect specific tasking effectively in the teaching process? 
(2)How to train the thought of computer program design through the understanding of the industry process?

(3) How to help students to use learning resources actively and to carry out the learning more effectively?

This research group has carried out a reform research projects of colleges and universities teaching in Jiangxi province. The project topic is "based on 'task-driven, learning-research combination' study and practice of computer programming courses classroom teaching modes in medical colleges ".

\section{The innovation of teaching design and implementation on computer programming courses in medical colleges and universities}

A realistic target model should be set up by read widely at home and abroad especially of classroom teaching mode of computer programming courses to carry out the research. The aim of the research group is complete two main goals. Firstly, reformulated based on the "task-driven" classroom teaching content and design. Secondly, implemented based on the "task-driven, learning and research integration" teaching mode reforms.

\subsection{Design based on the "task-driven" content of classroom teaching.}

(1) Investigate first.

In order to obtain the real tasks, the research group investigated the industry. Medical undergraduate majors in medical schools as the research object, to carry out the related units, professional (medical institutions, pharmaceutical production and sales enterprises) industry research.

Survey unit: The leading pharmaceutical enterprises in Ganzhou city of Jiangxi province, the First Affiliated Hospital of Gannan University.

Research purpose: It allowed the research group to understand the main process of hospital medical and management, and carry out the "task-driven" material for teaching plans and classroom tasks.

Main tasks:

1) Grasp the responsibility of the medical industry practitioners and main work processes by the investigation.

2) Draw flowcharts of work after investigation.

3) Select the appropriate workflow. In order to provide teaching materials and introduction for the practical teachings, the research group should select the appropriate workflow for the classroom teaching in programing.

Research overview:

The research group was started an investigation of pharmaceutical industry in Ganzhou city during the December 2012 to June 2013. Through research consultation, the main workflows of the medical establishment and the pharmaceutical industry were mastered. The research group chose suitable and interactive instance to integrate programming language materials and the design of teaching. In the actual teaching process, the research group leads to knowledge through cases of explaining the idea and method of programming, introduces the real case to analysis the key algorithm and processes, cultivates students' problem-solving skills and programming techniques by the experiment development.

(2) According to the result of the research, the research group is trying to use the method of taskdriven teaching model to design class-based task teaching.

The research group designed the classroom teaching based on the $\mathrm{C}$ language. For example: Selection structure is one of the basic structures in structured programming, with nested IF statement is the difficulty of teaching. The research group clarified the problem solving method of program design through the task-driven teaching method, formed the work of the specific industry process for real cases through investigation (flow chart shown in figure1), and illustrated the basic statements and logical expressions of select statement. 


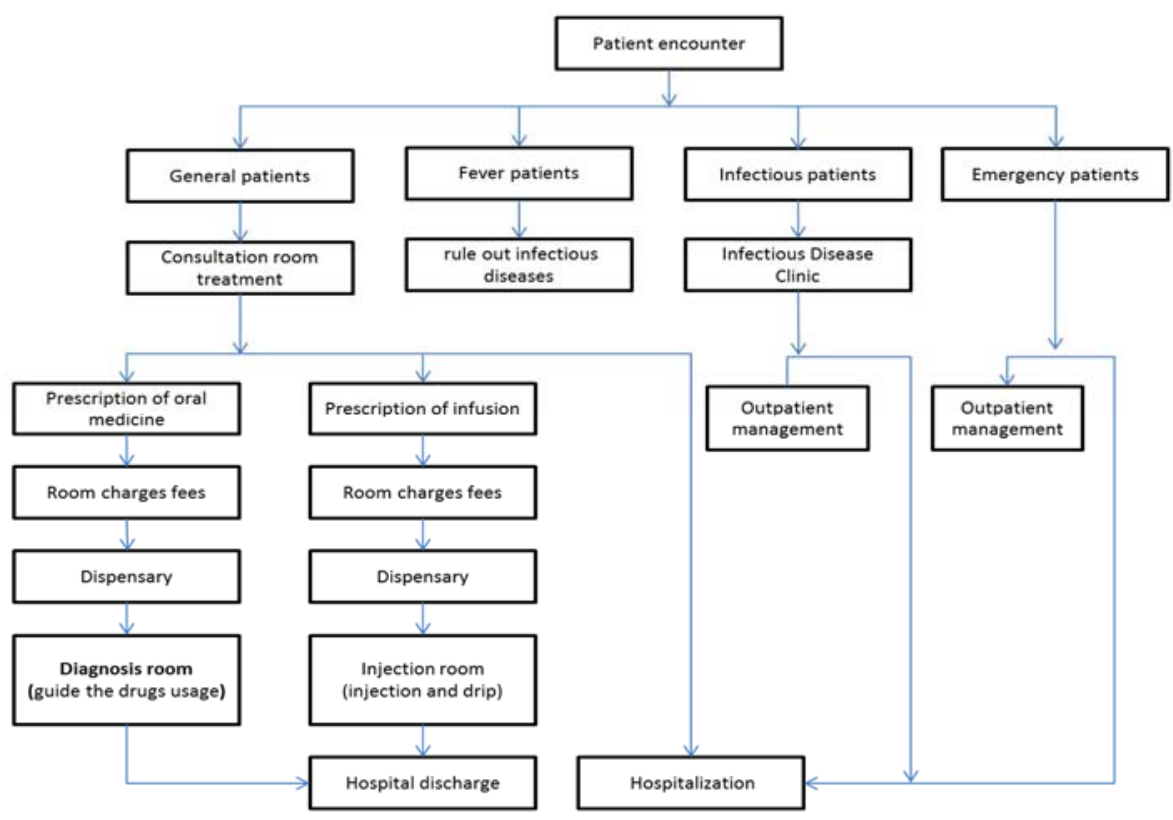

Figure 1: Flowcharts of hospital's processes

The feasibility and the degree of difficulty of the task is also an important aspect to consider. This must be done to accurately grasp the students' existing knowledge; it means to set up an appropriate task. In process of teaching programming, the research group will always break down tasks into smaller subtasks by simplifying the task. Detailed tasks make students clear about the specific direction and goals. When determining the overall task, therefore, the research group should fully consider the comprehensiveness of relevant knowledge, at the same time to lay out the task in detail, ensure the subtasks not too big which is in the scope of most of the students to be able to do.

\subsection{The reforms that based on the "task-driven, learning-research combination" of classroom teaching mode were implemented}

The research group established the classroom teaching mode that base on" Task-driven, goaloriented, objective-oriented and case study", and wrote the classroom teaching content and teaching practices.

Main ideas: Project was throughout the "task-driven teaching method" in the teaching of computer programming, integrated traditional methods. In classroom teaching, the research group combined the industry task with real cases based on the traditional teaching of programming. The members of author's research group obtained the real process that integrated into the classroom teaching design of programming through the research, created the real situations and teaching tasks, and focused on import and reference to case studies in real class. Extracurricular tasks assigned teachers to promote students ' independent study and get good results. The above are research based practice projects, whose main practice is as follows:

(1) Using case-based teaching methods, establishment real situation.

In order to make the students can learn in and the reality or similar situations, the research group launched an investigation of pharmaceutical industry research and got a real workflows. After finishing perfect, the research group in the actual classroom teaching design associated with the current teaching topic, real learning situation, guide the learners with a real "task" into the learning situation, make learning visual and visualization. For example: when we were in the teaching content of structured programming, the construction of a pharmaceutical production enterprise inventory control system as a real situation. Teachers introduced pharmaceutical enterprise inventory management process, put students in a real situation, solving problems of theory without practice in traditional classroom teaching.

(2)Determine the question (task).

In under the premise of establishment situation, the research group choose to study with the current theme is closely related to the content of teaching (task) as the center element of the learning content as well as an imminent matter for every student to deal with. For instance: How to build a drug 
manufacturing enterprise of raw material inventory control system as a practical task? Let the students to participate in the design. Let students break large task into small tasks, every small task combined with teaching content. For example, the function of inventory alerts can be combined with the programming in the branch of the structure of the teaching content, teaching taught the related knowledge to students at the same time, promoting the students thinking, set a valid condition, remind when condition is met, otherwise don't remind. This is a typical branch of structured programming ideas.

(3)Stimulate students' autonomous learning and collaborative learning.

When we ask questions and tasks, not immediately and directly by the teacher tells students how to solve the problem, instead, to provide students with a general industry process, and relevant clues to solve this problem. For example, the students need to collect what kind of resources. This is opening up issues and the solution of tasks, on the premise of students understand the process of the department, by looking up information, to get more knowledge of related industries, to activate the prior knowledge and experiences, to understand, analyze and solve the current problems.

Syntax problem solving and program design to meet together. Through the computer training, design procedures, to achieve effective work to master knowledge and deeply understand the industry process. Do the teaching practice: Theory - Reflection -Theory - Practice. It can not only provides the interface between new and old knowledge, to expand a good platform, also promotes communication between students, effectively constructs the knowledge, accord with the main characteristic of exploratory learning.

(4)Publish reference solution of tasks to help students' self-evaluation.

Learning outcomes assessment consists of two parts, one is for students to complete the current process of the solution and the result of evaluation. It means assessment of the meaning of what they have learned, and the more important aspect is the evaluation of students' autonomous learning and cooperative learning. Following the completion of a task, the instructor will provide a reference solution for student self-evaluation and discussion.

Therefore, it requires teachers to prepare for the related work before the classroom teaching, such as case discussions, lesson plan preparation, etc., and lay a solid foundation.

\section{Acknowledgements}

This work was financially supported by Colleges and universities teaching reform research projects in Jiangxi province (No. JXJG-12-12-03) in 2012; College of Humanities and social science research projects in Jiangxi province (No. SH1302) in 2013.

\section{References}

[1]Dongjin Yu, Wei Zhang, Ying Liu et al. Teaching with Successive Tasks and Approaches: A Case Study of Instruction on Materialized Views[J].Advanced Science Letters,2012,7:130-134.

[2]Adler, A. C.,Homayounrooz, F.F.. Medical student education improvement using a resident-driven student rotation [J].Southern Medical Journal, 2012, 105(2):68-70.

[3]Elisabet Comelles, Natalia Judith Laso, Montserrat Forcadell et al. using online databases in the linguistics classroom: dealing with clause patterns [J].Computer assisted language learning, 2013, 26(3):282-294.

[4]Qi ZHANG, Hao YANG, Yuguang WEI et al. Selection of Destination Ports of Inland-PortTransferring RHCTS Based on Sea-Rail Combined Container Transportation[C].//Innovation and sustainability of modern railway: Third international symposium on Innovation and sustainability of modern railway (ISMR 2012), September 20-21, 2012, Nanchang, China.2012: 675-680.

[5]LI Hai-hua. Discussion of Task-Driven Teaching Approach through Software Engineering Teaching[C].//MEMS, NANO and Smart Systems.2012:1706-1709. 